\title{
A new predilection site of Mycoplasma bovis: postsurgical seromas in beef cattle
}

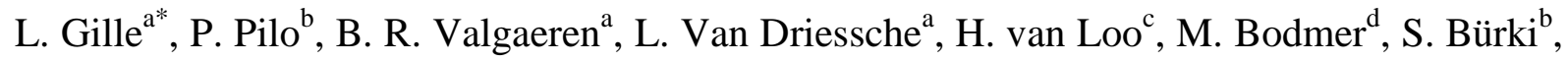
F. Boyen ${ }^{\mathrm{e}}$, F. Haesebrouck ${ }^{\mathrm{e}}$, P. Deprez ${ }^{\mathrm{a}}$, B. Pardon ${ }^{\mathrm{a}}$

${ }^{\mathrm{a}}$ Department of Large Animal Internal Medicine, Faculty of Veterinary Medicine, Ghent University, Salisburylaan 133, 9820 Merelbeke, Belgium

${ }^{\mathrm{b}}$ Department of Infectious Diseases and Pathobiology, Institute of Veterinary Bacteriology, 122 Laenggassstrasse, Postfach 8466, CH-3001 Bern, Switzerland

${ }^{\mathrm{c}}$ Animal Health Service Flanders, DGZ Vlaanderen, Industrielaan 29, 8820 Torhout, Belgium

${ }^{\mathrm{d}}$ Department for Clinical Veterinary Medicine, Clinic for Ruminants, Vetsuisse Faculty, University of Bern, Bremgartenstrasse 109A, 3001 Bern, Switzerland

${ }^{\mathrm{e}}$ Department of Bacteriology, Pathology and Avian Diseases, Faculty of Veterinary Medicine, Ghent University, Salisburylaan 133, 9820 Merelbeke, Belgium

*Corresponding author. Tel: +32-92647588; Fax: +32-92647796

E-mail: Linde.Gille@ugent.be

Running head: Mycoplasma bovis seromas in cattle

\section{Highlights:}

- Postsurgical seromas can be a predilection site of M. bovis in beef cattle

- Strains obtained from joints and udders are identical to M. bovis seroma strains

- M. bovis strain isolated from seromas can spread between farms

- M. bovis infected seromas are difficult to treat and have a poor prognosis 
2 Abstract

3 Mycoplasma bovis (M. bovis) is a highly contagious bacterium, which predominantly causes chronic

4 pneumonia, otitis and arthritis in calves and mastitis in adult cattle. In humans, Mycoplasma species

5 have been associated with post-surgical infection. The objective of the present study was to determine

6 the causative agent in three outbreaks of seromas after caesarian section in Belgian Blue beef cattle. A

7 total of 10 cases occurred in three herds which were in close proximity of each other and shared the

8 same veterinary practice. Mortality risk in referred animals positive for mycoplasma in a seroma was

$980 \%(4 / 5)$, despite intensive treatment. A massive increase in antimicrobial use occurred in every case

10 farm. M. bovis could be cultured from seroma fluid in $83.3 \%$ of sampled cases $(5 / 6)$, mostly in pure

11 culture and from chronic sites of infection (arthritis and mastitis). DNA fingerprinting of the isolates

12 targeting two insertion sequence elements suggested spread of M. bovis from chronic sites of infection

13 (udder and joints) to the postsurgical seromas. Identical strains were demonstrated in two animals

14 from two separate farms, suggesting contact between farms. These results confirm involvement of $M$. bovis in postsurgical seromas in cattle as in humans.

Key words: Mycoplasma bovis, caesarean section, seroma, DNA fingerprinting 


\section{Introduction}

Mycoplasma bovis is an emerging bacterium in cattle worldwide (Nicholas, 2011, Spergser et al., 2013). This pathogen is highly contagious and a single clone can spread rapidly after introduction into a naive herd (Soehnlen et al., 2012, Timsit et al., 2012). M. bovis has mainly been associated with chronic unresponsive pneumonia, otitis and (peri)arthritis in calves (Maunsell and Donovan, 2009) and with mastitis, arthritis and pneumonia in adult dairy cattle (Pfützner and Sachse, 1996). Occasionally M. bovis has been reported to cause infections of the tendon sheath (Gagea et al., 2006), keratoconjunctivitis (Alberti et al., 2006), meningitis (as a complication of otitis media/interna) (Stipkovits et al., 1993), myocarditis (Maunsell and Donovan, 2009), genital infections (vaginitis, abortion and vesiculitis) (Pfützner and Sachse, 1996) and decubital abscesses over the brisket and joints in calves (Kinde et al., 1993). Especially in chronic stages, the disease is characterized by a poor response to antimicrobial agents which compromises animal welfare, increases antimicrobial use and causes important economic losses such as weight loss, milk drop, loss of carcass quality, increased mortality/culling risk and increased veterinary costs (Maunsell et al., 2011).

Caesarian section (CS) is a common surgical procedure in Belgian Blue (BB) cattle due to the parturient complications linked to the muscular hypertrophy of this breed (Michaux and Hanset, 1986). Several pre-, peri- and postoperative complications of this surgical procedure have been described (Mijten, 1998, Kolkman et al., 2010). In BB cattle wound infection and seroma formation occur in $13 \%$ and $1 \%$ of CS cases, respectively (Mijten, 1998). A seroma is defined as a sterile fluid accumulation between subcutis, muscle layers and/or the peritoneum and is, also in human medicine, a well-known complication after surgery, including CS (Chelmow et al., 2004). Seromas can become infected either through hematogenous spread, surgical wound infection or iatrogenic by non-sterile punction (Chelmow et al., 2004).

This article reports on the involvement of $M$. bovis in an epidemic of infected seromas after CS on multiple farms belonging to a single veterinary practice. 


\section{Materials and Methods}

\section{Examination, clinical evaluation and sampling}

All study animals were adult BB cows that recently underwent CS, originating from three different BB beef herds (farm 1,2 and 3) of the same veterinary practice. All cows had a chronic site of infection (mastitis or arthritis), a non-responsive high fever and weight loss. The most chronic cases (cow 1 and 2) had been treated with penicillin, neomycin, lincomycin, spectinomycin, amoxicillin, florfenicol and enrofloxacin at the farm without any improvement. The animals were examined according to Rosenberger (1990). Transabdominal ultrasound was performed with a 7.5 MHz transducer (MyLab 25 Gold, Esaote Benelux). All animals had seromas intra-abdominally, visualized by ultrasound. Aspirations were performed under ultrasonographic guidance, using a $21 \mathrm{G}$ needle after local desensitization with procaine $4 \%$ (Procainii Chloridum $4 \%+$ adrenalinum, Kela, Hoogstraten, Belgium) and surgical preparation of the punction site. Samples consisted of seroma fluid (aspirations from live animals or swabs from the lesions taken at necropsy), joint fluid, milk and swabs of various affected organs post mortem.

\section{$\underline{\text { Microbiological identification }}$}

All samples (Table 1) were stored at $4^{\circ} \mathrm{C}$ and plated within 24 hours on Columbia agar plates supplemented with 5\% sheep blood and on a modified pleuropneumonia-like organism (PPLO) agar plate $\left(\mathrm{DIFCO}^{\mathrm{TM}}, \mathrm{BD}, \mathrm{NJ}\right)$ containing colistin sulphate, ampicillin, deactivated horse serum and yeast extract. Agar plates were incubated at $35^{\circ} \mathrm{C}$ in an atmosphere enriched with $5 \% \mathrm{CO}_{2}$. Blood agars and PPLO agars were incubated for 48 hours and 7 days, respectively. Bacterial isolates were subsequently identified to the species level with standard biochemical methods. Presumptive $M$. bovis identification was based on the typical fried-egg colony appearance on modified PPLO agar and the presence of lipase activity as tested on medium containing tween-80 (Devriese and Haesebrouck, 1991).

\section{Strain identification and typing by insertion sequence elements typing}

After mycoplasmal species confirmation by realtime PCR targeting the $u v r C$ gene of filter-cloned isolates (Rossetti et al., 2010), typing was performed by insertion sequence (IS) elements profiling on 6 M. bovis isolates (M1-M6) derived from cow 3 (M1, farm 1), cow 4 (M2-M3, farm 1) and cow 6 
(M4-M6, farm 3). Cow 5 (farm 2) could not be included because the sample was analysed by an external lab without preservation of the sample. DNA extractions from axenic cultures of $M$. bovis were carried out with the peqGOLD Bacterial DNA kit (Axonlab, Baden, Switzerland). IS element typing was performed as previously described (Thomas et al., 2005; Aebi et al., 2012). Briefly, genomic DNA was digested with the EcoRV restriction enzyme and DNA fragments were separated on a $0.7 \%$ agarose gel and further transferred on positively charged nylon membranes. ISMbov1 and ISMbov2 IS elements were further detected using digoxigenin-11-dUTP (dig) labelled probes as previously described (Pilo et al., 2003, Aebi et al., 2012).

\section{Results}

\section{Clinical evolution}

A total of 10 BB cows developed a postsurgical seroma between October 2014 and june 2015 (6 in herd 1, 1 in herd 2 and 3 in herd 3). Of these animals six were available for further examination in this study. Two chronically ill cows (cow 1 and 2 (Farm 1)) had a very poor body condition score (1 on a scale of 5) and were immediately euthanized for welfare reasons. Necropsy showed multiple large seromas in the abdomen (Figure 1), abscesses in the subcutis, a purulent mastitis on four quarters and arthritis in multiple joints in both animals. The third cow (cow 3) from farm 1 did not have seromas at entrance in the clinic, but developed a seroma on the left and right side of the abdomen some days after first examination. Blood examination showed a low selenium level $(51 \mu \mathrm{g} / \mathrm{l}$, ref: $70-100 \mu \mathrm{g} / \mathrm{l})$, leukocytosis and hyperproteinemia.. The animal was treated with several antibiotics, clinical response followed when treated with gamithromycin (Zactran ${ }^{\circledR}$, Merial ${ }^{\circledR}, 6 \mathrm{mg} / \mathrm{kg}$ intramuscular (IM), every 7 days) and neomycin and penicillin (Neopen ${ }^{\circledR}, \mathrm{MSD}^{\circledR}, 500 \mathrm{mg} / 100 \mathrm{~kg}$ Neomycin, 1.000.000 IU/100 $\mathrm{kg}$ penicillin IM, daily) for 5 weeks, together with draining and daily rinsing of the seromas with $0.05 \%$ of chlorhexidine. The animal was discharged after 35 days.

At the farm, the local veterinarian preventively medicated every cow with $2.5 \mathrm{mg} / \mathrm{kg}$ tulathromycin intramuscular immediately before CS and again 1 week after surgery, in an attempt to stop the 
development of new cases. In April 2015 a new case (cow 4; BB; 5 years old, 17 days post calving) occurred in the same farm. The animal initially presented fever, which did not respond to treatment with neomycin-penicillin, penicillin, tulathromycin, tylosin and trimethoprim-sulfonamide. The cow developed arthritis on both carpal joints and mastitis with sandy secretion on all quarters. Ultrasonography confirmed the presence of multiple fluid filled structures bilaterally in the abdomen. Necropsy showed multiple seromas and general lymphadenopathy. On blood examination, a very low selenium level was present $(16 \mu \mathrm{g} / \mathrm{l}$, ref.: $70-100 \mu \mathrm{g} / \mathrm{l})$.

In June 2015 two other farms, belonging to the same veterinary practice, were affected by the same condition. Multiple animals were affected, samples were taken from two animals (cow 5 from farm 2 and cow 6 from farm 3) (Table 1).

\section{Bacteriology and strain typing}

An overview of samples taken from the 6 cows with post-surgical seroma formation from the three farms, their bacteriological culture results are presented in Table 1. M. bovis was isolated in pure culture from the post-surgical seromas in 4 out of 5 cases sampled and in one case together with Trueperella pyogenes. From cow 2 no seroma fluid was collected. In several animals M. bovis was also cultured from the udder and/or joints.

IS elements typing showed an identical M. bovis strain in animals from herds 1 and 3 (cows 4 and 6, respectively) (Figure 2). In herd 1 the isolates from cow 3 (November) and cow 4 (April) were very similar, especially when using ISMbov1 IS elements, but not identical. Within one animal the same strain could be isolated from the udder, joints and the seromas (cows 4 and 6) (Figure 2).

\section{Discussion}

In human medicine, wound infection caused by Mycoplasma hominis is a described complication of CS (Phillips et al., 1987, Maccato et al., 1990). In the present study, M. bovis was isolated from seromas following CS in five cows from three different farms. To the author's knowledge the involvement of Mycoplasma spp. in wound infections or seromas in animals has not been reported 
earlier. Possibly the importance of M. bovis and other Mycoplasma spp. is underestimated, since the selective growth media required for their isolation are rarely used in routine bacteriological examinations of wound infections and Mycoplasma spp. either don't grow or are easily overgrown on regular blood agar plates.

M. bovis is known to spread hematogenous from the lungs to the joints (Maunsell and Donovan, 2009). The current case series strongly suggest hematogenous spread of M. bovis to the surgical incision site from a primary site of (chronic) infection as well, in this case most probably the udder and joints. It is not clear why this spread occurred, both virulence factors related to the strain or physiological immune suppression around parturition might play a role. Possibly, suppressed immunity around parturition facilitated dissemination of $M$. bovis. In the same way the low selenium levels of cow 3 and 4 might have played an additional role in the illness, as this deficiency has been linked to a lowered periparturient immunity level (Sordillo, 2013).

In the present outbreaks, the $M$. bovis infections resulted in a severe clinical presentation with a very poor outcome. A single animal could be saved after a long hospitalization period. The lack of clinical break points for $M$. bovis, made selection of an effective antimicrobial difficult, resulting in the use of different molecules. However, given the chronic state of disease at the time submission, little efficacy of antimicrobial therapy is to suspected and euthanasia is strongly advised for both economic and welfare reasons. Next to the loss of the animals, the condition resulted in a massive increase in antimicrobial use in the affected farms, partly due to therapy failure and partly due to the fear of farmer and veterinarian for the development of new cases. Despite the apparent improvement of the situation after preventive antimicrobial use, the authors wish to underscore that no evidence to support this measure is provided. In contrast, such prophylactic treatments might further increase antimicrobial selection pressure, selecting for multi-drug-resistant bacteria, including $M$. bovis isolates as recently reported in France (Gautier-Bouchardon et al., 2014).

A most interesting observation was the presence of an identical strain in two different farms, suggesting spread from one farm to the other. Direct spread through animal contacts was less probable since there were no connecting pastures or animal transports between the farms. Airborne transmission 
of M. bovis from one herd to another cannot be excluded, but has not yet been demonstrated in cattle (Soehnlen et al., 2012). Therefore, indirect spread through materials or persons, visiting both farms, is the most likely route of transmission. In farm 1 isolates from November and April were highly similar, but not identical, suggesting mutation of the original strain.

In conclusion, this report adds infection of post-surgical seromas to the list of $M$. bovis associated pathology. The condition can affect multiple cows in a short period and has a poor prognosis. Early detection by farmers and practitioners of animals with chronic sites of $M$. bovis infection and subsequent culling is likely the best option to prevent or contain this pathology. Appropriate biosecurity precautions should be taken by all farm visitors to prevent transmission among herds.

\section{Acknowledgements}

We would like to thank all technical staff of the departments of Bacteriology and Internal medicine and all involved farmers and veterinarians for their help and cooperation. The molecular biology part of this work was supported by the Swiss National Science Foundation (reference no. 31003A_160159 to Paola Pilo).

\section{Bibliography}

Aebi, M., M. Bodmer, J. Frey and P. Pilo, 2012: Herd-specific strains of Mycoplasma bovis in outbreaks of mycoplasmal mastitis and pneumonia. Vet Microbiol, 157, 363-368.

Alberti, A., M. F. Addis, B. Chessa, T. Cubeddu, M. Profiti, S. Rosati, A. Ruiu and M. Pittau, 2006: Molecular and Antigenic Characterization of a Mycoplasma Bovis Strain Causing an Outbreak of Infectious Keratoconjunctivitis. J Vet Diagn Invest, 18, 41-51.

Chelmow, D., E. J. Rodriguez and M. M. Sabatini, 2004: Suture closure of subcutaneous fat and wound disruption after cesarean delivery: a meta-analysis. Obstetrics \& Gynecology, 103, 974-980.

Devriese L.A. and F. Haesebrouck, 1991:. Antibiotic susceptibility testing of Mycoplasma bovis using tween 80 hydrolysis as an indicator of growth. J. Vet. Med., 38, 781-783.

Gagea, M. I., K. G. Bateman, R. A. Shanahan, T. van Dreumel, B. J. McEwen, S. Carman, M. Archambault and J. L. Caswell, 2006: Naturally Occurring Mycoplasma Bovis—Associated Pneumonia and Polyarthritis in Feedlot Beef Calves. J Vet Diagn Invest, 18, 29-40. 
Gautier-Bouchardon, A. V., S. Ferre, D. Le Grand, A. Paoli, E. Gay and F. Poumarat, 2014: Overall decrease in the susceptibility of Mycoplasma bovis to antimicrobials over the past 30 years in France. PloS one, 9 , e87672.

Kinde, H., B. M. Daft, R. L. Walker, B. R. Charlton and R. Petty, 1993: Mycoplasma-Bovis Associated with Decubital Abscesses in Holstein Calves. J Vet Diagn Invest, 5, 194-197.

Kolkman, I, G. Opsomer, D. Lips, B. Lindenbergh, A. De Kruif, S. De Vliegher, 2010: Pre-operative and operative difficulties during bovine caesarean section in Belgium and associated risk factors. Reprod Domest Anim., 45(6), 1020-1027.

Maccato, M., S. Faro and K. L. Summers, 1990: Wound Infections After Caesarean Section with Mycoplasma hominis and Ureaplasma urealyticum: A Report of Three Cases. Diagnostic Microbiology and Infectious Diseases, 363-365.

Maunsell, F. P. and A. Donovan, 2009: Mycoplasma bovis infections in Young Calves. Veterinary Clinics: Food Animal Practice, 139-177.

Maunsell, F. P., A. R. Woolums, D. Francoz, R. F. Rosenbusch, D. L. Step, D. J. Wilson and E. D. Janzen, 2011: Mycoplasma bovis infections in cattle. Journal of veterinary internal medicine / American College of Veterinary Internal Medicine, 25, 772-783.

Michaux, C. and R. Hanset, 1986: Mode de vêlage et reproduction chez les génisses de race Blanc-Bleu Belge des types viandeux et mixte. Ann. Méd. Vét., 439-451.

Mijten, P., 1998: Puerperal Complications After Cesarean Section in Dairy Cows and in Double-Muscled Cows. Reproduction in Domestic Animals, 33, 175-179.

Nicholas, R. A. J., 2011: Bovine mycoplasmosis: silent and deadly. Veterinary Record, 168, 459-462.

Pfützner, H. and K. Sachse, 1996: Mycoplasma bovis as an agent of mastitis, pneumonia, arthritis and genital disorders in cattle. Revue Scientifique et Technique de l' OIE, 1477-1494.

Phillips, L. E., S. Faro, S. F. Pokorny, P. A. Whiteman, K. H. Goodrich and R. M. Turner, 1987: Postcaesarean Wound Infection by Mycoplasma hominis in a Patient with Persistent Postpartum Fever. Diagnostic Microbiology and Infectious Diseases, 193-197.

Pilo, P., B. Fleury, M. Marenda, J. Frey and E. M. Vilei, 2003: Prevalence and distribution of the insertion element ISMag1 in Mycoplasma agalactiae. Vet Microbiol, 92, 37-48.

Rosenberger, G., 1990: Die klinische untersuchung des Rindes. Paul Parey Verlag, 3rd edition, Berlin, Germany 
Rossetti, B. C., J. Frey and P. Pilo, 2010: Direct detection of Mycoplasma bovis in milk and tissue samples by real-time PCR. Mol Cell Probes, 24, 321-323.

Soehnlen, M. K., A. Aydin, K. S. Murthy, E. J. Lengerich, A. L. Hattel, B. A. Houser, G. D. Fenton, H. R. Lysczek, C. M. Burns, A. M. Townsend, J. W. Brooks, D. R. Wolfgang and B. M. Jayarao, 2012: Epidemiology of Mycoplasma bovis in Pennsylvania veal calves. J Dairy Sci, 95, 247-254.

Sordillo, L. M., 2013: Selenium-Dependent Regulation of Oxidative Stress and Immunity in Periparturient Dairy Cattle. Veterinary Medicine International, 2013, 154045.

Spergser, J., K. Macher, M. Kargl, I. Lysnyansky and R. Rosengarten, 2013: Emergence, re-emergence, spread and host species crossing of Mycoplasma bovis in the Austrian Alps caused by a single endemic strain. Vet Microbiol, 164, 299-306.

Stipkovits, L., M. Rády and R. Glávits, 1993: Mycoplasmal arthritis and meningitis in calves. Acta veterinaria Hungarica, 41, 73-88.

Thomas, A., A. Linden, J. Mainil, D. F. Bischof, J. Frey and E. M. Vilei, 2005: Mycoplasma bovis shares insertion sequences with Mycoplasma agalactiae and Mycoplasma mycoides subsp. mycoides SC: Evolutionary and developmental aspects. FEMS microbiology letters, 245, 249-255.

Timsit, E., M. A. Arcangioli, N. Bareille, H. Seegers and S. Assie, 2012: Transmission dynamics of Mycoplasma bovis in newly received beef bulls at fattening operations. J Vet Diagn Invest, 24, 1172-1176. 
Figures and tables

227

Figure 1: Fluid accumulation between the greater omentum and peritoneum in a 4 year old cow (cow 4 ) suffering from multiple Mycoplasma bovis infected seromas.

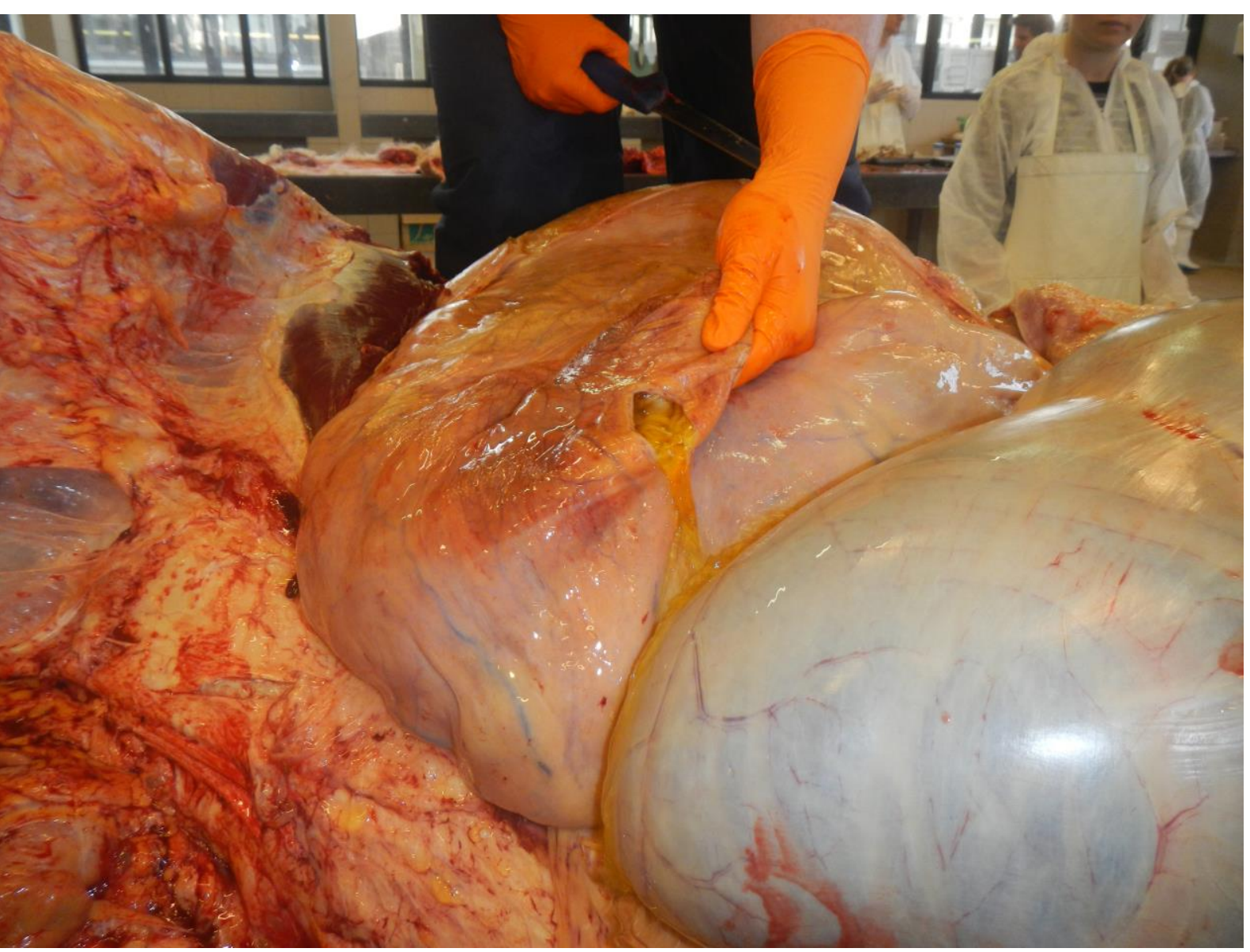


Figure 2: Southern blots of $M$. bovis isolates from cows with postsurgical seroma formation after

\section{ISMbovl}

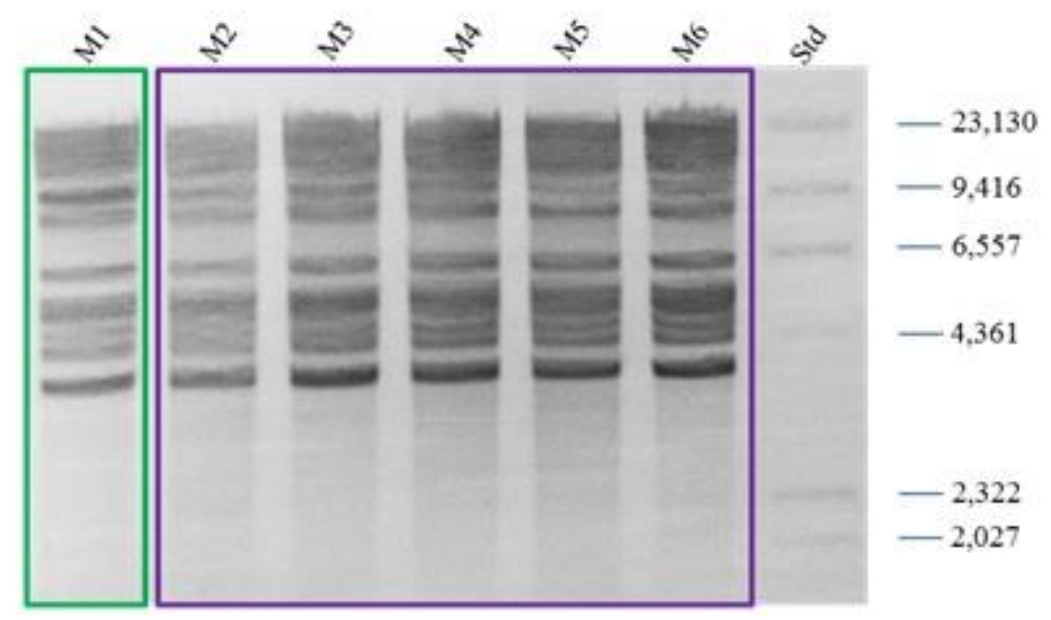

\section{ISMbov2}

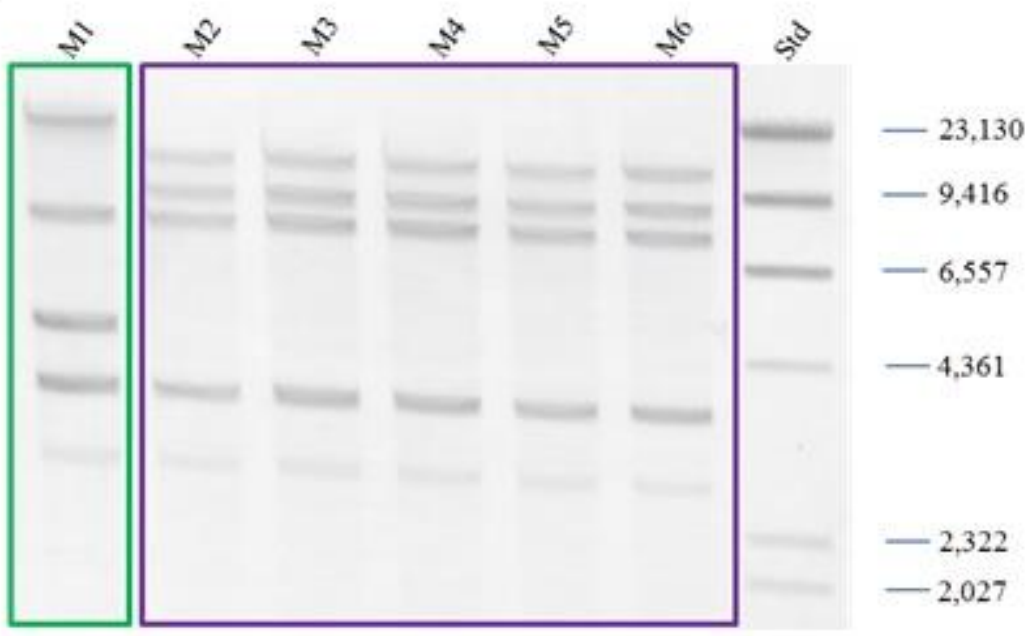

M1: Seroma of cow 3, farm 1, November 2014. M2: Seroma of cow 4, farm 1, April 2015. M3: Udder cow 4, farm 1, April 2015. M4: Udder cow 6, farm 3, June 2015. M5: Joint fluid cow 6, farm 3, June 2015. M6: Seroma cow 6, farm 3, June 2015. Std: DNA Molecular Weight Marker II, DIG-labeled (Roche)

Table 1. Bacterial culture results from different sampling sites of 6 beef cows with post-surgical seroma formation.

\begin{tabular}{|c|c|c|c|c|c|c|}
\hline & Cow 1 & Cow 2 & Cow 3 & Cow 4 & Cow 5 & Cow 6 \\
\hline \multicolumn{7}{|l|}{ Sampling site } \\
\hline Joints & T. pyogenes and M. bovis & M. bovis & N/A & N/A & N/A & T. pyogenes and $M$. bovis \\
\hline Udder & T. pyogenes and M. bovis & M. bovis & M. bovis & M. bovis & N/A & T. pyogenes and $M$. bovis \\
\hline Kidney & N/A & Negative & N/A & N/A & N/A & N/A \\
\hline Lung & Negative & N/A & N/A & N/A & N/A & Negative \\
\hline
\end{tabular}


M. bovis: Mycoplasma bovis; T. pyogenes: Trueperella pyogenes; A. fumigatus: Aspergillus fumigatus, N/A: not available Cow 1-4: Farm 1, Cow 5: Farm 2, Cow 6: Farm 3.

237

238

239 